\title{
Simulation and analysis of an isolated full- bridge DC/DC boost converter operating with a modified perturb and observe maximum power point tracking algorithm
}

\author{
Calebe A. Matias \\ Giordani Pacífico Medeiros \\ Pedro H. F. Moraes \\ Bruno de A. Fernandes \\ Aylton J. Alves \\ Experimental and Technological Research and \\ Study Group (NExT) \\ Federal Institute of Goias (IFG), Goiânia, \\ Brazil \\ Email: calebeabrenhosa@gmail.com
}

\author{
Wesley P. Calixto \\ Geovanne P. Furriel \\ School of Electrical, Mechanical and Computer \\ Engineering \\ Federal University of Goiás (UFG), Goiânia, \\ Brazil \\ Email: w.p.calixto@ieee.org
}

\begin{abstract}
- the purpose of the present study is to simulate and analyze an isolated full-bridge DC/DC boost converter, for photovoltaic panels, running a modified perturb and observe maximum power point tracking method. The zero voltage switching technique was used in order to minimize the losses of the converter for a wide range of solar operation. The efficiency of the power transfer is higher than $90 \%$ for large solar operating points. The panel enhancement due to the maximum power point tracking algorithm is $5.06 \%$.
\end{abstract}

Index Terms - energy efficiency, geometric Brownian motion, Monte Carlo simulation, performance measurement and verification, solar water heating.

\section{INTRODUCTION}

HE concern to produce clean energy is relevant in $\mathrm{T}_{\text {view }}$ of the global warming and pollution. The search for new technologies to improve power conversion of renewable energy sources is the focus of studies and discussions in many academics centers and industries across the globe [1].

Photovoltaic (PV) panels are made of photosensitive semi- conductors. Their semiconductor cells are hit by solar radiation and produce a difference of potential. The problem is that panels cannot deliver the maximum power by their own considering the impedance matching principle. That is the main reason for using a power converter running a maximum power point tracking (MPPT) algorithm [2].

$\mathrm{DC} / \mathrm{DC}$ converters are used to change the impedance seen by any source, due to control of the trigger circuit of these switches [3]. A DC/DC converter is needed when speaking at tracking the maximum power of an energy source, as a photovoltaic panel [4].

The analysis of the behavior and power transfer ratios of a converter can determine its efficacy on deliver the maximum power to the load. A computer simulation provides lots of information about these characteristics. This can be used to help the development of a real converter [5].

This paper aims to analyze the power transfer ratios and the modified perturb and observe (P\&O) MPPT performance of an isolated full-bridge $\mathrm{DC} / \mathrm{DC}$ boost converter considering the power loss on its components in order to verify the feasibility of the development of a real device [6], [7].

In order to minimize the losses on the switches of the converter the zero voltage switching technique was applied to trigger the MOSFETs.

To perform the analysis of the results and approach of the electrical model of a photovoltaic panel was made for generating its characteristic curve. Later, there were made an analysis of the operation of the DC-DC converter and observations on the MPPT technique. 


\section{Methodology}

A simulation was performed aiming to analyze the power transfer ratio for a wide range of solar operation and the MPPT method.

\section{A. Materials}

The selected PV panel was KC200GT from KYOCERA, with 54 cells. Its main electrical performance under standard test conditions (irradiance $1000 \mathrm{~W} / \mathrm{m}^{2}$, AM 1.5 spectrum and module temperature at $25^{\circ} \mathrm{C}$ ) data are shown in Table I. The simulation was performed with SPICE software (Simulation Program with Integrated Circuits Emphasis).

TABLE I

ELECTRICAL PERFORMANCE UNDER STANDARD TEST CONDITIONS

\begin{tabular}{ll}
\hline \hline Maximum Power & $200 \mathrm{~W}(+10 \% /-5 \%)$ \\
Maximum Power Voltage & $26.3 \mathrm{~V}$ \\
Maximum Power Current & $7.61 \mathrm{~A}$ \\
Open circuit Voltage & $32.9 \mathrm{~V}$ \\
Short circuit Current & $8.21 \mathrm{~A}$ \\
Max System Voltage & $600 \mathrm{~V}$ \\
Temperature Coefficiente of VOC & $-1.23 \times 10^{-1} \mathrm{~V} /{ }^{\circ} \mathrm{C}$ \\
Temperature Coefficient of ISC & $3.18 \times 10^{-3} \mathrm{~A} /{ }^{\circ} \mathrm{C}$ \\
Area & $1.41 \mathrm{~m}^{2}$ \\
\hline \hline
\end{tabular}

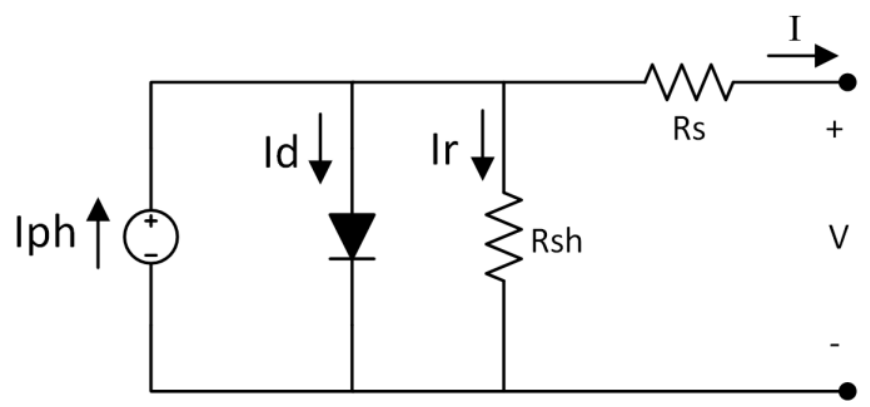

Fig. 1. Single-diode model of the photovoltaic module.

\section{B. Electrical model of a photovoltaic panel}

There are several electrical models that describe the behavior of a photovoltaic panel, among them stands out the model with one diode, one series resistance and one resistor in parallel [8], [9], as shown in Fig. 1.

Applying Kirchhoff's law on the circuit, the equation of the load current is obtained as in (1).

$$
I=I_{p h}-I_{d}-I_{r}
$$

Where $I_{p h}$ is the current generated by the photovoltaic effect, $I_{d}$ is the current in the diode and $I_{r}$ is the current in $R_{s h}$.

The $I_{p h}$ current is dependent on the solar radiation and temperature as (2).

$$
I_{p h}=\left[I_{p h, s t c}+K i\left(T-T_{s t c}\right)\right] \frac{G}{G_{s t c}}
$$

Where $I_{p h, c}$ is the current generated by the photovoltaic effect under standard conditions, $K_{i}$ is the temperature coefficient of the short circuit current, $T_{s t c}$ is the temperature at standard conditions $\left(25^{\circ} \mathrm{C}\right), \mathrm{G}_{s t c}$ is the radiation at standard conditions $\left(1000 \mathrm{~W} / \mathrm{m}^{2}\right)$.

The current in the diode $\left(I_{d}\right)$ has a non-linear characteristic and is dependent on such factors as the saturation current $\left(I_{0}\right)$, the Boltzmann constant $(k)$, the electron charge $(q)$, the ideality factor $\left(a_{1}\right)$ and the number of cells in series $\left(n_{s}\right)$ as (3).

$$
I_{D}=I_{0}\left\{\exp \left[\frac{q \times\left(V+I \times R_{s}\right)}{n_{s} \times k \times T \times a_{1}}\right]-1\right\}
$$

The calculation of the saturation current considers the temperature coefficient of open circuit voltage $\left(K_{v}\right)$, temperature coefficient of short circuit current $\left(K_{i}\right)$, the short circuit current $I_{s c}$ under standard conditions $\left(I_{S, s t c}\right)$ and the open circuit voltage under standard conditions $\left(V_{O C, s t c}\right)$ as $(4)$.

$$
I_{0}=\frac{I_{S, s t c}+k i\left(T-T_{s t c}\right)}{\exp \left[\frac{q\left(V_{O C, s t c}+k v\left(T-T_{s t c}\right)\right)}{\left(n_{s} \times K \times T\right)}\right]-1}
$$

The current through the resistor in parallel is as (5).

$$
I_{R}=\frac{V+I \times R_{S}}{R_{S h}}
$$

There are two other important parameters needed to be calculated: the value of $R_{s h}$ and $R_{s}$. These values lead the calculated maximum power point match the experimental maximum power point $\left(V_{m p} \times I_{m p}\right)$. An iteration algorithm, under PyLab environment, that increases the value of $R_{s}$ to estimate the $I_{p h, c}, I_{p h}$ and $R_{s h}$ values as (2), (6) and (7).

$$
I_{p h, s t c}=\frac{R_{s h}+R_{s}}{R_{s h}} I_{s c, s t c}
$$

$$
R_{s h}=\frac{V_{m p}\left(V_{m p}+I_{m p} \times R_{s}\right)}{\left[V_{m p}+I_{p h}-I_{d}-P_{\max , E}\right]}
$$


The characteristic curve of the photovoltaic panel was obtained using a computational algorithm. The following values of parallel $\left(R_{s h}\right)$ and series $\left(R_{S}\right)$ resistances used on simulation were:

$$
\begin{gathered}
R_{S h}=158.66 \Omega \\
R_{S}=0.0053 \Omega
\end{gathered}
$$

\section{Modified perturb and observe MPPT method}

This method was proposed by [7]. The classical P\&O MPPT algorithm considers that the PV power variation is caused by only the PV voltage perturbation. In fact the $\mathrm{PV}$ power is influenced by both the converter and the environ- mental conditions, such as irradiance and temperature.

During rapidly irradiance changing period, on conventional $\mathrm{P} \& \mathrm{O}$ method, there is a wrong control signal due to simple observation of the PV power and voltage reference. Fig. 2 represents the PV power curve at irradiance $I_{1}$ and irradiance $I_{2}$. Considering that the conventional $\mathrm{P} \& \mathrm{O}$ algorithm is running from point $\mathrm{A}$ to point $\mathrm{B}$, trying to reach point $\mathrm{D}$, at irradiance $I_{1}$, so the control signal must increase the voltage from $V_{1}$ to a short period of time $(\Delta t)$ and soon back to irradiance $I_{1}$, the converter might read the power at point $\mathrm{C}$ and the next control signal must decrease power, for with the increasing voltage and the power reduction the algorithm will try to reach the maximum power point running the opposite way of the real condition, point $\mathrm{D}$. So the conventional perturb and observe method fails to track the maximum power point [7].

To fix this issue a modified P\&O MPPT algorithm is needed. This method consists in distinguish the power variation caused by the MPPT control and the irradiance. This can be done by adding a PV power measurement between of control period. The diagram in Fig. 3 illustrates the process. Where $d P_{0.5}$, shown in (8), is the power difference between the middle-point $\left(d P_{k-0.5}\right)$ and

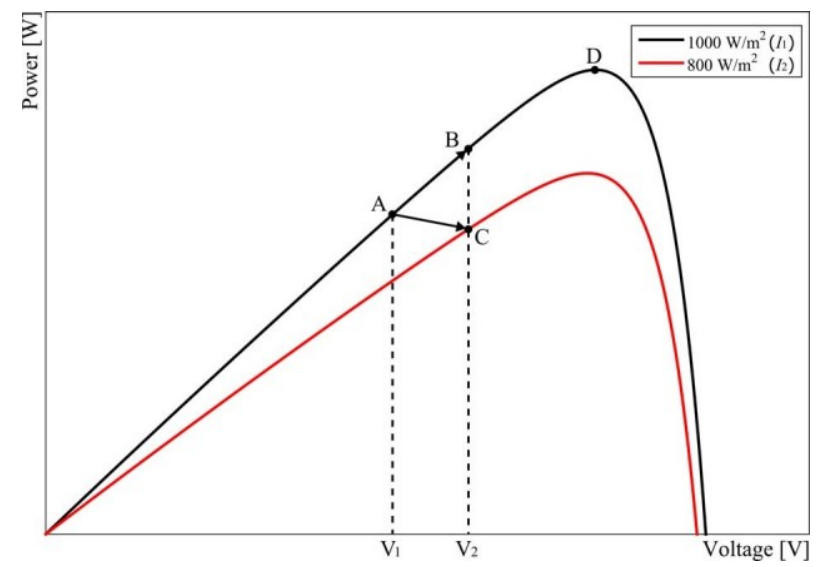

Fig. 2: Control signal analysis of the conventional P\&O. the starting point $\left(d P_{k-1}\right)$, which contains the power of both solar radiation and MPPT control; $d P_{1}$, shown in (9), contains the power caused by only the irradiance variation and $d P$, shown in (10), is the power caused by only the MPPT control [10] [7].

$$
\begin{gathered}
d P_{0.5}=P(k-0.5)-P(k-1) \\
d P_{1}=P(k)-P(k-0.5) \\
d P=d P_{0.5}-d P_{1}
\end{gathered}
$$

So the algorithm uses the power variation caused by only the MPPT control signal to track the maximum power point. This fixes the problem of the conventional P\&O method.

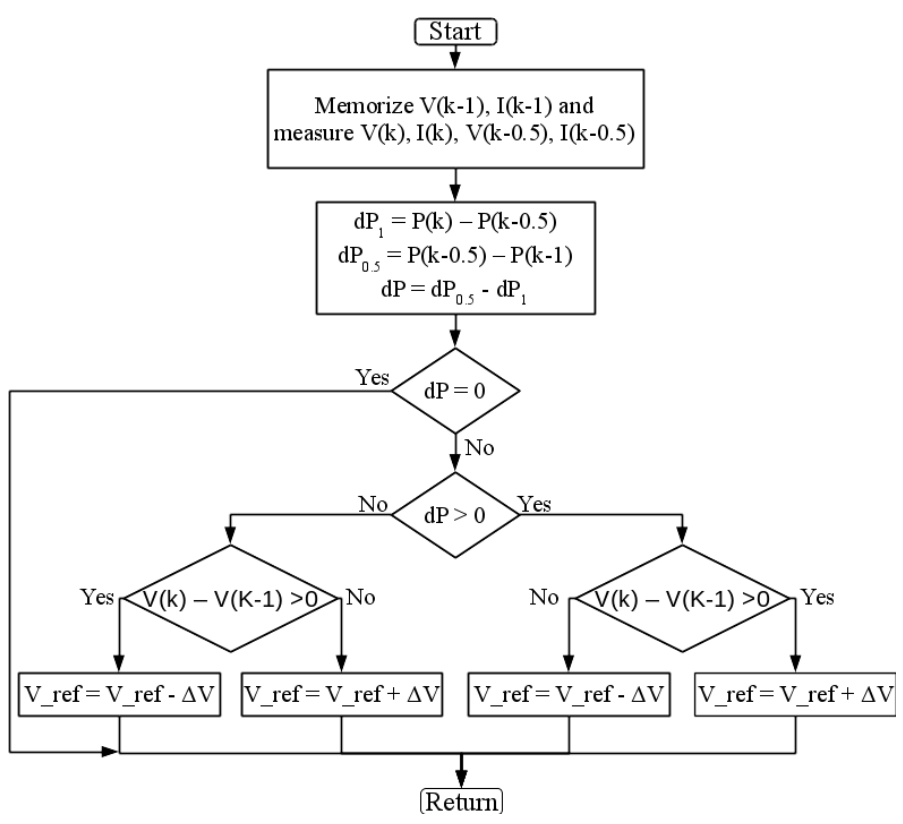

Fig. 3: Modified P\&O algorithm method.

\section{Simulation AND RESUltS}

Using SPICE software a simulation was performed to determine the voltage and current values of each component. 
The schematic in Fig. 4 represents the circuit used in the simulation. An algorithm running the mathematic model of the solar panel provides the voltage $V_{P V}$ to DCDC converter.

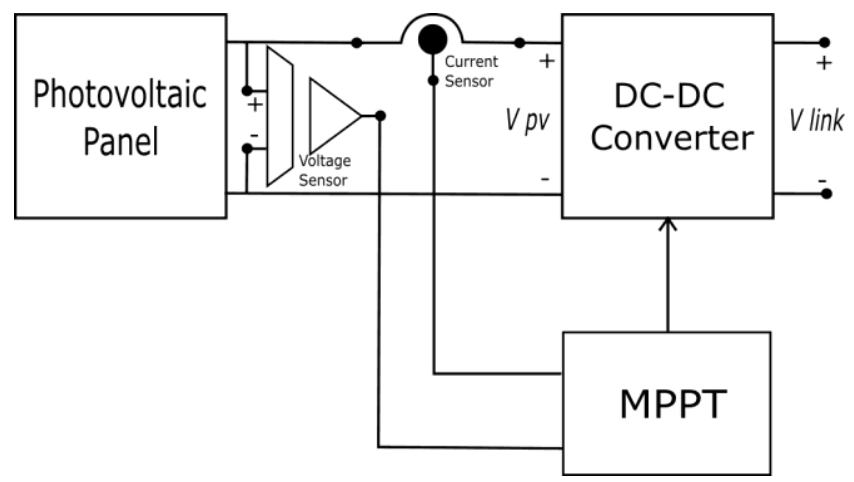

Fig. 4: Schematic of the circuit used in simulation.

\section{A. Operating mode of full-bridge DC/DC boost converter}

The isolated full-bridge DC/DC converter, depicted in Fig. 5, working as a step-up or boost converter. $V_{P V}$ is the operating voltage of the photovoltaic panel, which can be varied until the open circuit voltage limit $\left(V_{o c}\right)$. The use of $C_{P V}$ decoupling capacitor is recommended to prevent the effects of high frequency current ripple generated by the converter, in the photovoltaic panel.

The MOSFETs are used to generate an alternating waveform in the primary of the transformer with a duty

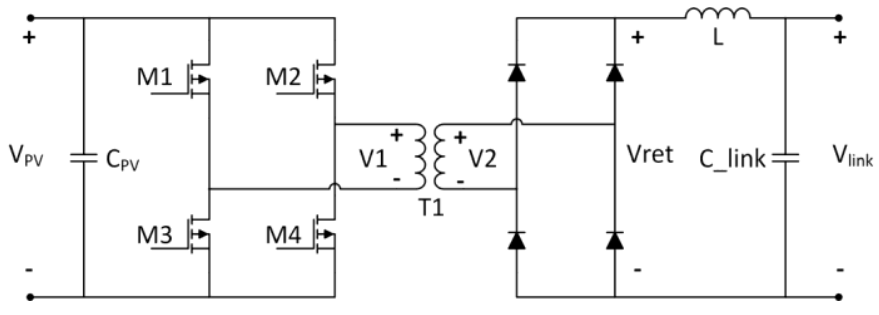

Fig. 5: DC-DC Isolated Full Bridge Power Converter Circuit.

cycle frequency equals $110 \mathrm{kHz}$. Fig. 6 shows the actuation cycle of the MOSFETs and the waveform generated in the primary of the transformer (V1). A charge/discharge time on the MOSFETs generate losses for there is voltage and current over them at the same time. To minimize these losses a Zero Voltage Switching (ZVS) technique is used. Therefore a time period in which the voltage at the primary of the transformer (V1) remains zero due to the use of this technique, so the switching time of the MOSFETs are different, depicted in Fig. 6.

The transformer amplifies the voltage at a ratio of $n$. The next stage is rectifying this voltage and then filters the current e voltage ripple through the inductor $\mathrm{L}$ and the capacitor C_Link.
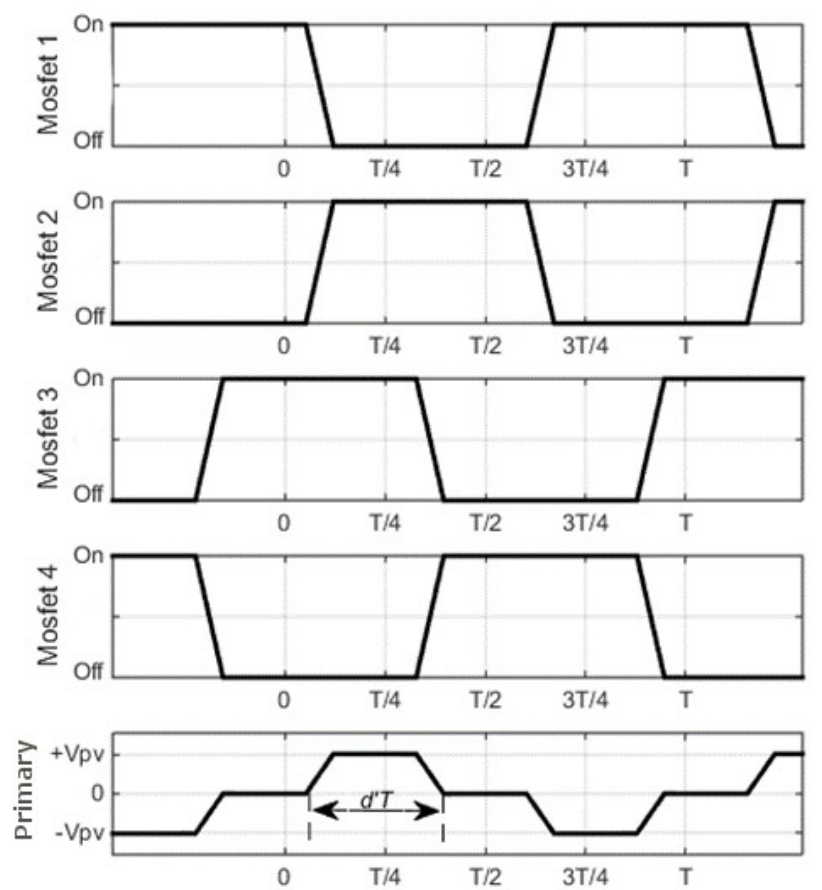

Fig. 6: MOSFETs waveform of the converter.

The DC link voltage is:

$$
V_{\text {link }}=n \times V_{P V} \times 2 d^{\prime}
$$

The duty cycle of the MOSFETs switching is equal D, where $\mathrm{D}=2 . \mathrm{d}$ '. The voltage blanking time (voltage equals zero) in the primary of the transformer (V1) is changed by the duty cycle of effective work d' $=D / 2$, as depicted in Fig 6.

The simulation was performed under standard conditions, so the commercial electronic components are specified for its limits values. A load resistance was attached at the DC-DC converter, so measurements can be made. The voltage and current values were observed on each component; therefore the list of commercial components is determined, seen in Table II.

The performance analysis of the DC/DC converter is performed using the specification of the components of the Table II. A 1:18 transformer ratio was used to elevate the voltage to the desired level.

After running a new simulation, varying the solar radiation, the values on the Table III was obtained. This information shows that the converter works properly under wide range of solar operation points and it keeps the efficiency higher than $90 \%$ for operation points above $5 \%$. When the solar panel is operating under low solar radiation the converter loses the efficiency and the MPPT algorithm does not work effectively. 
Fig. 7 represents the output power of the panel due to suddenly irradiance variation. When the irradiance gets from $1000 \mathrm{Wm}^{2}$ to $800 \mathrm{~W} / \mathrm{m}^{2}$ the output power decreases. The implemented modified P\&O MPPT has a batter dynamic response than the classic.

\section{B. Modified $P \& O M P P T$ analysis}

The modified P\&O MPPT method was proposed to correct the MPPT control signal during rapidly solar radiation changing. During steady state both methods work properly, but when the irradiance changes suddenly the recovery time on the modified algorithm is faster than the classic.

TABLE II

COMPONENTS USED IN THE SIMULATION

\begin{tabular}{ll}
\hline \hline Component & Specification \\
\hline Panel KC200GT & $200 \mathrm{~W}$ \\
$C_{\text {in }}$ & $330 \mathrm{uF}$ \\
Mosfets & Rson $=0.07 \Omega, 16 \mathrm{~A}, 60 \mathrm{~V}$ \\
Diodes & $1000 \mathrm{~V}, 2 \mathrm{~A}$ \\
L & $12 \mathrm{mH}, 5 \Omega$ \\
Transformer & $1: 18$ \\
C_link & $30 \mathrm{uF}, 450 \mathrm{~V}$ \\
$C_{\text {out }}$ & $1000 \mathrm{nF}, 275 \mathrm{Vac}$ \\
\hline \hline
\end{tabular}
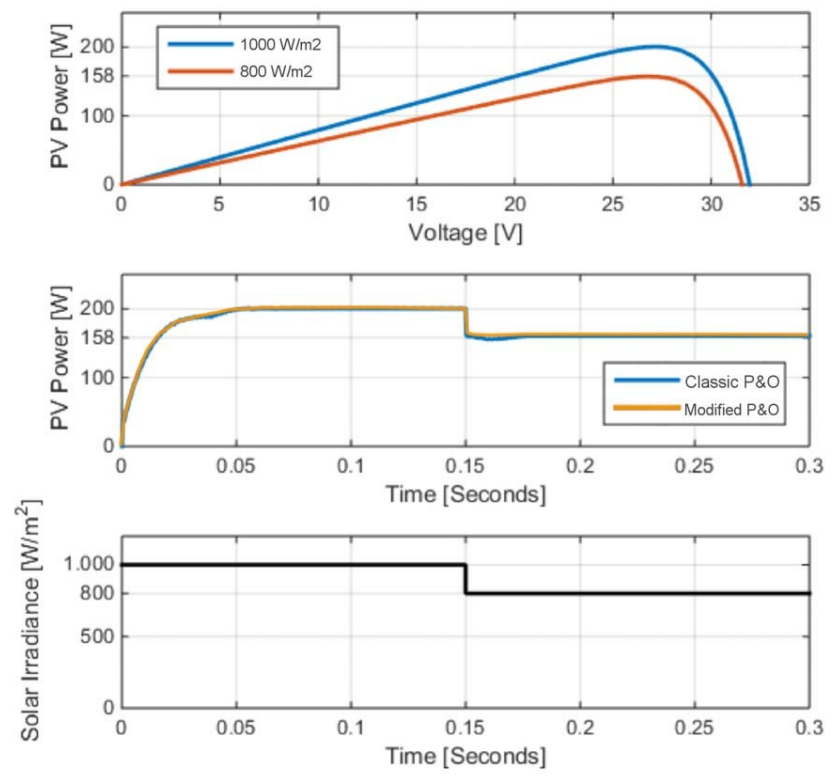

Fig. 7: Modified P\&O MPPT response.

The efficiency of the panel, $\eta$, can be evaluated as:

$$
\eta=\frac{\int_{0}^{T} p(t) d t}{A_{c} \int_{0}^{T} G(t) d t}
$$

where $p(t)$ is the power output of the panel, $\mathrm{G}(t)$ is the solar radiation and $A_{c}$ is the area of the panel.

A comparison between the panel efficiency under the conditions depicted in Fig. 7 using both algorithms gives that the conventional and the modified $\mathrm{P} \& \mathrm{O}$ efficiency is respectively $12.24 \%$ and $12,86 \%$. So the enhancement on panel efficiency, using the modified P\&O method, was $5.06 \%$, compared to classical method.

The efficiency of the panel considers the integration on time interval $[0, T]$, which means as more irradiance variation over the panel, during the time, higher is its efficiency gain, for the time recovering of the power is lower than conventional $\mathrm{P} \& \mathrm{O}$.

TABLE III

SIMULATION RESULTS OF THE DC-DC CONVERTER.

\begin{tabular}{|c|c|c|c|c|}
\hline $\begin{array}{l}\text { PV Operation } \\
\text { Point }\end{array}$ & $\begin{array}{c}5 \% \\
(10 W)\end{array}$ & $\begin{array}{l}25 \% \\
(50 W)\end{array}$ & $\begin{array}{l}50 \% \\
(100 W)\end{array}$ & $\begin{array}{l}100 \% \\
(200 W)\end{array}$ \\
\hline PV voltage: & & & & \\
\hline $\begin{array}{l}\text { Medium } \\
\text { voltage [V] }\end{array}$ & 24.55 & 27.35 & 26.11 & 26.15 \\
\hline PV current: & & & & \\
\hline $\begin{array}{l}\text { Average } \\
\text { current }[\mathrm{A}]\end{array}$ & 0.4304 & 1.73 & 3.83 & 7.65 \\
\hline PV power [W] & 10.56 & 47.42 & 100.04 & 200 \\
\hline $\begin{array}{l}\text { Duty Cycle [\%] } \\
\text { DC Link voltage: }\end{array}$ & 8.17 & 15.96 & 24.81 & 35.48 \\
\hline $\begin{array}{l}\text { Medium voltage } \\
{[\mathrm{V}]}\end{array}$ & 67.73 & 146.72 & 212.66 & 298.79 \\
\hline $\begin{array}{l}\text { DC link current: } \\
\text { Average current } \\
\text { [A] }\end{array}$ & 0.1354 & 0.29345 & 0.424533 & 0.59759 \\
\hline $\begin{array}{l}\text { Power DC Link } \\
\text { [V] }\end{array}$ & 9.17 & 43.05 & 90.45 & 179.33 \\
\hline $\begin{array}{l}\text { Equivalent load } \\
\text { resistance }[\Omega]\end{array}$ & 500.22 & 499.98 & 499.99 & 499.99 \\
\hline Efficiency [\%] & 87 & 91 & 90 & 90 \\
\hline
\end{tabular}

\section{CONCLUSION}

The performed simulations with the commercial specified components shows that the isolated full-bridge $\mathrm{DC} / \mathrm{DC}$ boost converter is efficient because it keeps its efficiency above $90 \%$ almost in the entire operation range.

The modified P\&O MPPT improved the power conversion compared to the classic method. The panel efficiency enhancement was $5.06 \%$. The results could be better for a real condition of solar radiation, in view of the quick irradiance variation on time due to shadows caused by clouds. 
The result shows that the physical implementation of the device is feasible.

\section{ACKNOWLEDGMENT}

The authors would like to thank Coordination for the Improvement of Higher Education Personnel (Capes), the National Counsel of Technological and Science Development (CNPq) and Research Support Foundation of Goias State (FAPEG) for financial support research and scholarships.

\section{REFERENCES}

[1] M. I. Hofferta et al., "Advanced technology paths to global climate stability: Energy for a greenhouse planet," Science, vol. 298, pp. 981- 987, 01 Nov 2002.

[2] B. Parida, S. Iniyanb, and R. Goic, "A review of solar photovoltaic technologies," Renewable and Sustainable Energy Reviews, vol. 15, pp. 1625-1636, 2011.

[3] M. H. Rashid, Power electronics handbook, third edition ed. Butterworth-Heinemann, 2010.

[4] N. Femia, G. Petrone, G. Spagnuolo, and M. Vitelli, Power Electronics and Control Techniques for Maximum Energy Harvesting in Photo- voltaic Systems. CRC Press, 2013.

[5] M. G. Villalva, M. F. Espindola, T. G. de Siqueira, and E. Ruppert, "Modeling and control of a three-phase isolated grid-connected converter for photovoltaic applications," Revista Controle \& Automação, vol. 22, no. 3, pp. 215228, 2011.

[6] S. B. Kjær, "Design and control of an inverter for photovoltaic applications," Ph.D. dissertation, Fac. of Eng. and Science, Aalborg University, Denmark, Aalborg, Jan. 2005.

[7] B. Yu, "An improved dynamic maximum power point tracking method for pv application," IEICE Electronics Express, vol. 11, no. 2, pp. 1-10, 2014.

[8] M. G. Villalva, J. R. Gazoli, and E. R. Filho, "Comprehensive approach to modeling and simulation of photovoltaic arrays," IEEE Transactions on Power Eletronics, vol. 24, no. 5, pp. 1198-1208, 2009.

[9] G.P. Medeiros, "Analysis and simulation of the p\&o mppt algorithm using a linearized pv array model," 10th Brazilian Power Electronics Conference (COBEP), 2009.

[10] L. Piegari, R. Rizzo, I. Spina, and P. Tricoli, "Optimized adaptive perturb and observe maximum power point tracking control for photovoltaic generation," Energies 2015, vol. 8, pp. 3418-3436, 2015. 